\title{
Follicular center helper T-cell (TFH) marker positive mycosis fungoides/Sezary syndrome
}

\author{
Howard J Meyerson $^{1}$, Amad Awadallah ${ }^{1}$, Peter Pavlidakey ${ }^{1}$, Kevin Cooper ${ }^{2}$, Kord Honda ${ }^{2}$ \\ and John Miedler ${ }^{1}$
}
${ }^{1}$ Department of Pathology, Seidman Cancer Center, University Hospitals Case Medical Center, Cleveland, OH, USA and ${ }^{2}$ Department of Dermatology, Seidman Cancer Center, University Hospitals Case Medical Center, Cleveland, $\mathrm{OH}, \mathrm{USA}$

\begin{abstract}
We identified 11 patients with CD10 $(+)$ cutaneous T-cell lymphoma by flow cytometry. All cases were CD4( + ) and CD8 $(-)$. Three patients had extensive lymphadenopathy, systemic symptoms and an aggressive clinical course consistent with angioimmunoblastic T-cell lymphoma or peripheral T-cell lymphoma. However, 8 of the 11 patients had a prolonged disease course with gross morphology, histology and tumor cell phenotype indistinguishable from mycosis fungoides or Sezary syndrome. Immunohistochemical studies confirmed CD10 expression in seven of the eight cases and revealed the lymphoma cells were Bcl-6(+), PD-1(+), and EBV $(-)$. Two had significant expression of $\mathrm{CXCL}-13(+)$. The findings indicate that lymphoma cells from mycosis fungoides or Sezary syndrome may express follicular center helper T-cell markers CD10, Bcl-6, and PD-1 and occasionally CXCL-13. The expression of these markers in some cases of mycosis fungoides/Sezary syndrome suggests follicular center helper T-cell differentiation and may lead to confusion in distinguishing mycosis fungoides/Sezary syndrome from other follicular center helper T-cell marker positive T-cell lymphomas with cutaneous manifestations.
\end{abstract}

Modern Pathology (2013) 26, 32-43; doi:10.1038/modpathol.2012.124; published online 24 August 2012

Keywords: Bcl-6; CD10; cutaneous T-cell lymphoma; flow cytometry; follicular helper T-cell; mycosis fungoides; Sezary syndrome

CD10 is a cell surface glycoprotein with endopeptidase activity that is expressed on a variety of hematopoietic and epithelial cells. ${ }^{1}$ CD10 expression has been described on a number of cells types and neoplasms that involve skin including the perifollicular fibrous sheath of the hair follicle, dermal fibroblasts, neutrophils, germinal center B cells, lymphomas of germinal center cell origin, melanoma, atypical fibroxanthoma and a variety of mesenchymal tumors. ${ }^{2-12}$ Additionally, CD10 is expressed on a subset of $\mathrm{CD} 4(+) \mathrm{T}$ cells residing in the lymph node follicle germinal center termed follicular helper T cells. ${ }^{13}$ These $\mathrm{T}$ cells are also known to express PD-1, CXCL-13, CD57, CXCR5, SAP, and ICOS with their differentiation controlled by Bcl-6. ${ }^{14-19}$

Some T-cell lymphomas express follicular center helper T-cell markers including CD10, suggesting derivation from follicular center helper T cells. ${ }^{15,20-35}$ These include angioimmunoblastic T-cell lymphoma,

Correspondence: Dr Howard Meyerson, MD, Department of Pathology, University Hospitals Case Medical Center, 11100 Euclid Avenue, Cleveland OH 44106, USA.

E-mail: hjm2@case.edu

Received 26 December 2011; revised 1 May 2012; accepted 1 May 2012; published online 24 August 2012 peripheral T-cell lymphoma with a follicular growth pattern, primary cutaneous CD4 $(+)$ small/ medium-sized pleomorphic T-cell lymphoma and, occasionally, peripheral T-cell lymphoma, not otherwise specified and anaplastic large cell lymphoma. ${ }^{15,20-35}$

Clinically, primary cutaneous CD4(+) small/ medium-sized pleomorphic T-cell lymphoma and angioimmunoblastic T-cell lymphoma present or may present with primary cutaneous involvement. ${ }^{20,36-40}$ Other CD4(+) T-cell lymphomas with primary cutaneous manifestations include mycosis fungoides and its variants including Sezary syndrome, adult T-cell leukemia/lymphoma and primary cutaneous $\mathrm{CD} 30+$ lymphoproliferative disorders. ${ }^{41}$ CD10 has not been reported to be a feature of mycosis fungoides or Sezary syndrome. ${ }^{41}$

Primary cutaneous CD4(+) small/medium-sized pleomorphic T-cell lymphoma is an indolent lymphoma that usually manifests as solitary plaque or nodule on the upper torso or face. Patches, as seen in mycosis fungoides, are lacking. The cells in primary cutaneous $\mathrm{CD} 4(+)$ small/medium-sized pleomorphic T-cell lymphoma frequently express the follicular center helper T-cell-associated markers PD-1, and CXCL-13 but infrequently CD10. ${ }^{20,34}$ 
Angioimmunoblastic T-cell lymphoma is an aggressive nodal-based disease that involves skin in roughly $50 \%$ of individuals. ${ }^{38-40}$ The neoplastic $\mathrm{T}$ cells in angioimmunoblastic T-cell lymphoma express the follicular center helper T-cell markers CD10, PD-1, and CXCL-13 in the majority of cases. ${ }^{27,41-43}$ Angioimmunoblastic T-cell lymphoma is also notable for an association with EBV as $70 \%$ or more angioimmunoblastic T-cell lymphoma lesions contain $\mathrm{EBV}(+) \mathrm{B}$ cells, a finding helpful in establishing the diagnosis. ${ }^{44}$ Peripheral T-cell lymphomas may express follicular center helper T-cell markers with or without a follicular growth pattern. These lymphomas have morphologic findings that overlap with, and may be indistinguishable from, angioimmunoblastic T-cell lymphoma. ${ }^{26}$

Detection of CD10 on tumor cells in skin biopsies by immunohistochemistry can be difficult due to expression of CD10 on tumor-associated dermal fibroblasts obscuring the cellular origin of the staining. ${ }^{6,7,42}$ As an alternative to immunohistochemistry, CD10 on tumor cells can be detected by flow cytometry. Previously, we have had success in evaluating $\mathrm{T}$ cells isolated from skin biopsies using flow cytometry. ${ }^{45-47}$ Here, we report CD10 expression on 11 T-cell lymphomas with primary cutaneous manifestations detected by flow cytometry. Although three of these cases exhibited features consistent with angioimmunoblastic T-cell lymphoma or peripheral T-cell lymphoma, the remaining (8 of 11) were best classified as mycosis fungoides or Sezary syndrome and expressed the follicular center helper T-cell-associated markers bcl-6 and PD-1. The findings indicate that follicular center helper T-cell marker positive T-cell tumors with cutaneous manifestations include mycosis fungoides and its variants.

\section{Materials and methods}

\section{Patients}

Patients with skin biopsies or blood specimens sent to the Flow Cytometry Laboratory at University Hospitals Case Medical Center to evaluate for mycosis fungoides or Sezary syndrome from 2003 to 2011 were reviewed for the presence of a CD10 $(+)$ abnormal (neoplastic) T-cell population. ${ }^{45-47}$ In all, 148 skin biopsies from 136 patients were sent to the Flow Cytometry Laboratory for evaluation. An abnormal T-cell population was identified in 50 of these patients. Of these, 36 were ultimately considered to have mycosis fungoides or Sezary syndrome. Six $(16.7 \%)$ of the mycosis fungoides/ Sezary syndrome patients had tumor cells that were $\mathrm{CD} 10(+)$ in at least one sample. Fourteen patients with abnormal T-cell populations from a skin biopsy did not have mycosis fungoides or Sezary syndrome. Three of these 14 patients had CD10 $(+)$ tumor cells. All three had an aggressive clinical course with systemic symptoms and lymphadenopathy. Lymph node biopsies performed in these three patients were consistent with angioimmunoblastic T-cell lymphoma or peripheral T-cell lymphoma. Two additional patients had abnormal CD10 $(+)$ T cells identified from peripheral blood flow cytometry. Therefore, in total, 11 patients were identified in which one or more specimens contained an abnormal CD10 (+) T-cell population. Flow cytometry data, skin biopsy histology and clinical data on these patients were reviewed for this study. Clinical data were obtained from review of the medical records after IRB approval.

\section{Histology}

Representative hematoxylin-eosin-stained histologic sections were available in six patients (patients $1,3,4,9,10$, and 11) and evaluated for epidermitropism and dermal infiltrate density on a 0-3 scale and dermal location (superficial, mid, or deep). Cytologic atypia of each lesion was evaluated by determining the percentage of hyperchromatic or large lymphoid cells. Cases were evaluated by two investigators ( $\mathrm{HM}$ and $\mathrm{PP}$ ) with concordance reached by examining the sections together. Immunoperoxidase stains were performed on formalin-fixed, paraffin-embedded tissue in the standard manner and evaluated for the CD4/CD8 ratio and tumor cell expression of CD10, Bcl-6, PD-1, CXCL-13 was determined as a percentage of total lymphoid cells. We also evaluated CD45RB/CD45RO epidermal staining discordance (epidermal CD45RB $(+)$ lymphocytes lacking CD45RO), a feature previously described as an indicator of neoplasia in CTCL-MF not found in reactive infiltrates. ${ }^{48} \mathrm{CD} 45 \mathrm{RB} / \mathrm{CD} 45 \mathrm{RO}$ epidermal staining discordance is present in $\sim 80 \%$ of mycosis fungoides or Sezary syndrome lesions. ${ }^{48}$ The presence of Epstein-Barr virus RNA was assessed by in situ hybridization staining with Epstein-Barr virus-encoded RNA 1 and 2 oligonucleotide probes on paraffin-embedded tissue sections as per the manufacturer's directions. Antibodies and reagents were purchased from Dako, Carpinteria, CA, USA (CD3, CD4, CD8, CD45RB, and CD45RO), Leica, Buffalo Grove, IL (CD10, Bcl-6), Abcam, Cambridge MA (PD-1), R\&D Systems, Minneapolis, MN, USA (CXCL-13) and Ventana, Tucson, AZ, USA (Epstein-Barr virus RNA) and were used according to the manufacturer's recommendations. Staining for CD10 and Bcl-6 was performed on the Leica Bond-Max and staining for PD-1, CXCL-13 and in situ staining for Epstein-Barr virus RNA on the Ventana Benchmark.

\section{Flow Cytometry}

For flow cytometry, 8-mm skin punch biopsy specimens were placed in cold RPMI and transported to the flow cytometry laboratory where the specimens were processed and analyzed within $24 \mathrm{~h}$ of receipt 
as previously described. ${ }^{45}$ Tissue specimens (skin and lymph node) were mechanically minced and incubated with $3.5 \mu \mathrm{g} / \mathrm{ml}$ of collagenase II (Sigma Chemical, St Louis, MO, USA) and $300 \mu \mathrm{g} / \mathrm{ml}$ of trypsin inhibitor, type II-O (Sigma) at $37^{\circ} \mathrm{C}$ for $1 \mathrm{~h}$ with rocking, then filtered over a $40-\mu \mathrm{m}$ nylon mesh. The isolated cells were washed once and resuspended in $2 \mathrm{ml}$ of Minimum Essential Medium Eagle Spinner Modification (S-MEM) media and used for staining. Four-color direct immunofluorescent staining was performed on $200 \mu \mathrm{l}$ of blood, bone marrow or tissue cell suspensions using the stain-wash-lyse method with antibody concentrations and incubation times as recommended by the manufacturer. The following antibodies were used for this analysis: CD2-PE, CD3-FITC and -APC, CD4APC, CD5-FITC, CD7-PE, CD8-PE, CD10-PE, CD19APC, CD23-PE, CD25-PE, CD26-FITC, CD30-PE, CD45-PerCP, CD45RA-FITC, CD45RO-PE, HLA-DRFITC, anti- $\kappa$-FITC, and anti- $\lambda$-PE. All monoclonal antibodies used in this study were purchased from BD BioSciences (San Jose, CA, USA). For skin biopsies, tubes were aspirated until dry to maximize cell recovery. Cells were acquired and analyzed on a FACSCalibur flow cytometer (BD BioSciences) using Cellquest software (BD BioSciences) from 2003 to 2009. From 2009 to 2011, samples were analyzed on a FACSCanto flow cytometer (BD BioSciences) using Diva software (BD BioSciences). Roughly 25000 total cells from skin biopsies were recovered. In all, 100000 total cells were acquired from other tissue sources. Tumor cells were identified by abnormal antigen expression and/or scatter profile as previously described. ${ }^{45-47}$ An abnormal CD4 $(+)$ T-cell population was considered present if there was a discrete cluster of CD4(+) T cells (20 or more cells) based on FSC x SSC, CD45 x SSC or CD3 gating and cells within the gated population demonstrated a phenotypic abnormality defined as altered or absent expression of CD2, CD3, CD4, CD5, CD7, or CD26. ${ }^{45-47}$

\section{Molecular Analysis}

TCR gene rearrangement was assessed by PCR using oligonucleotide consensus primers specific for the T-cell receptor $\gamma$ gene variable and joining regions. Studies were performed on DNA extracted from fresh frozen tissue, tissue sections obtained from formalin-fixed, paraffin-embedded blocks, or peripheral blood. The limit of detection for the assay is roughly 1 in 100 cells. The studies were performed at ARUP Laboratories, Salt Lake City, UT, USA.

\section{Results}

In all, 34 specimens from 11 patients with cutaneous T-cell lymphoma or suspected Sezary syndrome contained an abnormal CD10 $(+)$ T-cell population by flow cytometry, Figure 1, top. In all cases, the abnormal cells were CD4(+) and CD8(-). Review of patient data indicated that, in total, there were 60 flow cytometry samples from these 11 patients of which 43 samples were from blood, 12 from skin, 4 from lymph node, and 1 from bone marrow, Table 1. In all, 53 of the 60 analyses were positive for an abnormal T-cell population; however, in four patients, the detection of CD10 on the neoplastic cells was seen in only a portion of the specimens as indicated in Table 1. In two, CD10 expression became evident on the tumor cells some time after the diagnosis was made. In these samples, CD10 expression was noted on the lymphoma cells 6 months (patient 9) and 3 years (patient 3) after the initial detection of an abnormal T-cell population. In summary, 34 of the 53 'positive analyses' contained a discernable population of abnormal CD10 $(+) \mathrm{T}$ cells, Table 1.

The neoplastic CD10(+) T population was observed by flow cytometry in skin biopsies from eight patients (patients 1, 2, 4, 5, 6, 7, 8, and 10) and in the peripheral blood in six (patients $3,6,7,9,10$, and 11). Two of these latter patients (patients 3 and 9) did not have additional tissue evaluated by flow cytometry. Four patients (patients 6, 7, 10, and 11) had flow cytometry of the skin and blood, Figure 2. Three patients (patients 5, 6, and 8) had atypical CD10 $(+) \mathrm{T}$ cells detected by flow cytometry in lymph node biopsies as well as skin. All three of these patients were classified as angioimmunoblastic T-cell lymphoma or peripheral T-cell lymphoma.

The patients fell into two groups. Eight patients had clinical disease indistinguishable from mycosis fungoides or Sezary syndrome, Table 2, and are described below. The remaining three patients (patients 5, 6, and 8) had an aggressive clinical course with systemic symptoms and lymphadenopathy and lymph node biopsies consistent with angioimmunoblastic T-cell lymphoma or peripheral T-cell lymphoma. Two of these patients died of disease 1 and 2 years after diagnosis. This patient group will not be discussed further.

\section{Patients with Mycosis Fungoides/Sezary Syndrome (patients 1,2,3,4,7,9,10,11)}

Clinical Features. These patients consisted of seven men and one woman with a median age of 67 years, ranging from 54 to 85 years, Table 2. Sites of involvement of disease included areas commonly involved by mycosis fungoides; axilla (3/8), abdomen (3/8), arms (4/8), back (3/8), shoulders (2/8), chest (2/8), thigh (3/8), and head and neck (3/8), Table 2. Erythematous patches or plaques typical for mycosis fungoides were seen in 6/8, Figure 3 . Papules were seen in 2/8. Both of these patients also had patches or plaques. Generalized erythroderma was present in three patients. Four were clinically classified as mycosis fungoides, two as 

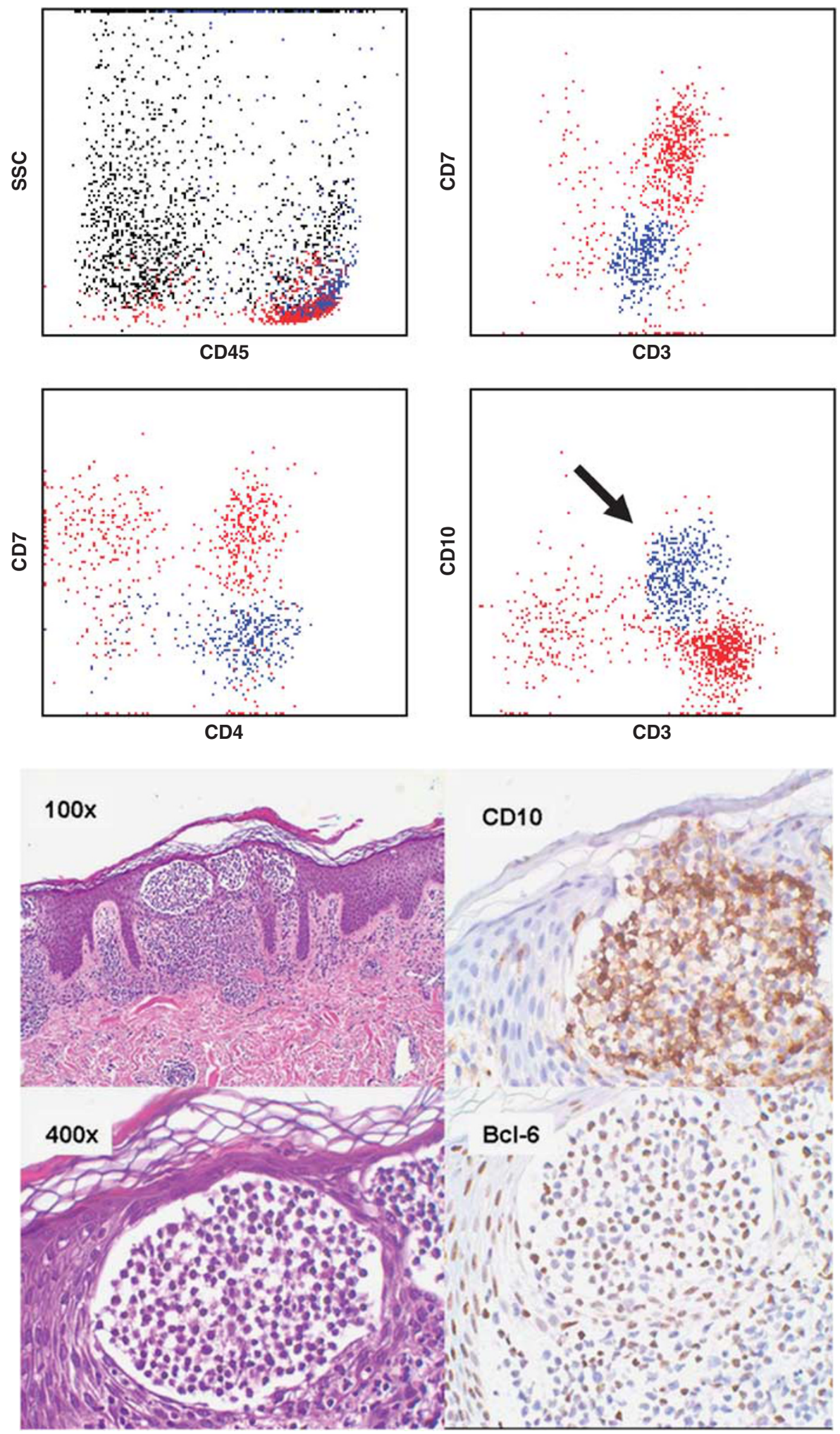

Figure 1 Skin biopsy flow cytometry and immunohistochemistry demonstrating expression of CD10 in mycosis fungoides. Flow cytometry dot plots are shown at the top; corresponding histology is shown at the bottom. For flow cytometry, mycosis fungoides cells are highlighted in blue, normal lymphocytes are in red. Mycosis fungoides cells generally have slightly greater side scatter and CD45 expression than normal lymphocytes. ${ }^{45-47,58}$ In this example, the cells are CD3dim, CD4( + ) with a normal expression level, CD7 ( -$)$ and $\mathrm{CD} 10(+)$. Note that CD10 is expressed only on the CD3dim cells (arrow). At the bottom, hematoxylin and eosin-stained tissue sections and immunohistochemical stains for CD10 and Bcl-6 are shown. Data are from patient 10. 
Table 1 FCM specimens from patients with CD10(+) cutaneous T-cell lymphoma

\begin{tabular}{|c|c|c|c|c|c|c|c|}
\hline \multirow[t]{2}{*}{ Patient } & \multirow[t]{2}{*}{ FCM specimens } & \multicolumn{4}{|c|}{ FCM specimen type } & \multirow{2}{*}{$\begin{array}{c}\text { FCM with abnormal } \\
\text { T cells }\end{array}$} & \multirow{2}{*}{$\begin{array}{c}\text { FCM with abnorma } \\
C D 10(+) T \text { cells }\end{array}$} \\
\hline & & Skin & Blood & Lymph node & Bone marrow & & \\
\hline 1 & 1 & 1 & - & - & - & 1 & 1 \\
\hline 2 & 1 & 1 & - & - & - & 1 & 1 \\
\hline 3 & 16 & - & 16 & - & - & 16 & $3^{\mathrm{a}}$ \\
\hline 4 & 1 & 1 & - & - & - & 1 & 1 \\
\hline 5 & 3 & 1 & - & 1 & 1 & 3 & 3 \\
\hline 6 & 8 & 2 & 5 & 1 & - & 8 & 8 \\
\hline 7 & 4 & 2 & 2 & - & - & 4 & 4 \\
\hline 8 & 3 & 2 & - & 1 & - & 3 & $2^{b}$ \\
\hline 9 & 9 & - & 9 & - & - & 9 & $8^{\mathrm{C}}$ \\
\hline 10 & 8 & 1 & 7 & - & - & 6 & $2^{\mathrm{d}}$ \\
\hline 11 & 6 & 1 & 4 & 1 & - & 1 & $1^{\mathrm{e}}$ \\
\hline Total & 60 & 12 & 43 & 4 & 1 & 53 & 34 \\
\hline
\end{tabular}

${ }^{\mathrm{a} C D} 10$ noted to be positive 3 years after initial $\operatorname{FCM}(+)$.

${ }^{\mathrm{b}}$ One skin specimen CD10 negative.

${ }^{\mathrm{C}}$ First specimen negative, remainder positive.

d Skin positive, one blood negative for T-cell abnormality; CD10 very weak and partial in one blood specimen.

${ }^{e}$ First blood positive, remainder negative; skin and lymph node negative but uninvolved by disease.

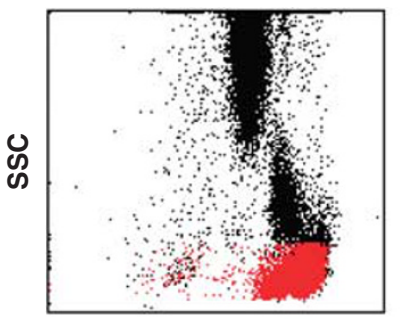

CD45

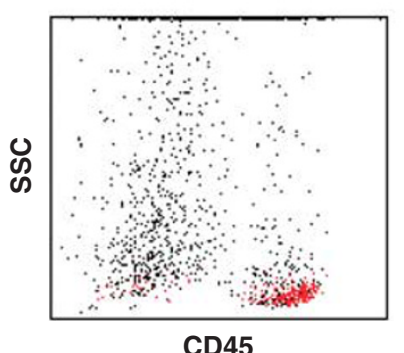

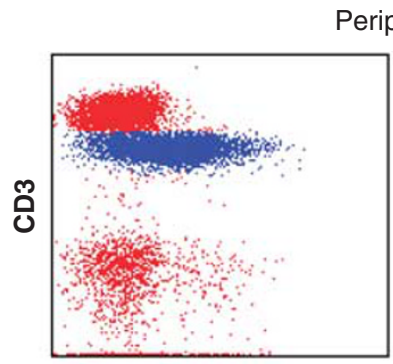

CD10

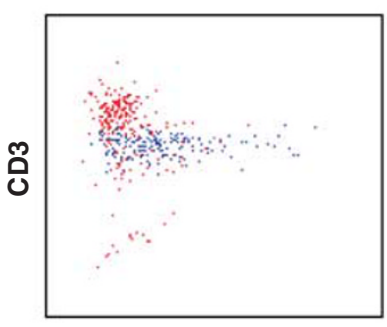

CD10
Peripheral blood
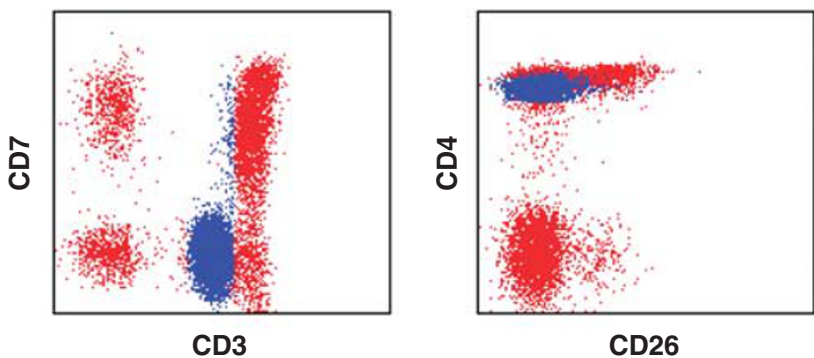

Skin
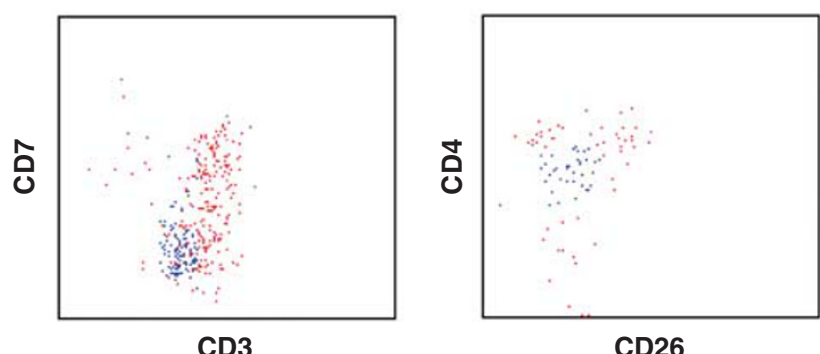

Figure 2 Flow cytometry demonstrating CD10 expression on mycosis fungoides/Sezary syndrome cells in peripheral blood and skin from the same patient. Mycosis fungoides/Sezary syndrome cells are highlighted in blue, normal lymphocytes are in red. Mycosis fungoides/Sezary syndrome cells are not indicated in the CD45 $\times$ SSC plots. In this example, the lymphoma cells are CD3dim, CD7( - ), $\mathrm{CD} 4(+)$, with slightly reduced expression, CD26( - ) and partially CD10 $(+)$. Lymphoma cell phenotype in the peripheral blood mirrors that in the skin biopsy. Data are from patient 7.

Sezary syndrome, and two as mycosis fungoides with Sezary syndrome.

Histology. Histology and immunohistochemistry of representative skin biopsies from these patients were examined. Histologic features are summarized in Table 3 and were typical of mycosis fungoides. Example of the histology is shown in Figure 4 and the bottom of Figure 1. All cases demonstrated a superficial lymphoid dermal infiltrate varying from sparse to dense. Most cases (6/8) exhibited moderate to marked lymphoid infiltrate. Significant epidermitropism was present in 50\%. The percentage of atypical enlarged or hyperchromatic cells varied, ranging from $<5 \%$ to $50 \%$ of the lymphocytes. Immunohistochemical staining revealed a high CD4/ CD8 ratio (10:1 or greater) in all cases examined, Figure 4. In all, 4/8 showed CD45RB/CD45RO 
Table 2 Clinical findings in patients with CD10(+) CTCL-MF or SS

\begin{tabular}{|c|c|c|c|c|c|c|c|c|}
\hline$P t$ & $\begin{array}{l}\text { Gender/ } \\
\text { age }\end{array}$ & $\begin{array}{l}B S A \\
(\%)\end{array}$ & $\begin{array}{c}\text { Clinical } \\
\text { diagnosis }\end{array}$ & Skin sites & $\begin{array}{l}\text { Disease } \\
\text { duration } \\
\text { (years) }\end{array}$ & Gross morphology & Outcome & Therapies \\
\hline 1 & M/ 65 & $>10 \%$ & CTCL-MF & $\begin{array}{l}\text { Shoulders, axilla, } \\
\text { abdomen, groin, } \\
\text { arms, } \\
\text { temples,back }\end{array}$ & 10 & $\begin{array}{l}\text { Erythematous } \\
\text { patches/plaques }\end{array}$ & $\begin{array}{l}\text { Progressive } \\
\text { disease }\end{array}$ & $\begin{array}{l}\text { Bexarotene, MTX, topical } \\
\text { steroids, NBUVB, nitrogen } \\
\text { mustard, photo therapy }\end{array}$ \\
\hline 2 & $\mathrm{~F} / 54$ & $<5 \%$ & CTCL-MF & $\begin{array}{l}\text { Arms, axilla, } \\
\text { lateral } \\
\text { chest, abdomen }\end{array}$ & 6 & Erythematous patches & $\begin{array}{l}\text { Limited disease } \\
\text { progression }\end{array}$ & $\begin{array}{l}\text { Bexarotene, nitrogen mustard, } \\
\text { photo therapy }\end{array}$ \\
\hline 3 & $\mathrm{M} / 85$ & $>95 \%$ & SS & Generalized & 7 & $\begin{array}{l}\text { Generalized erythroderma } \\
\text { with patches and plaques }\end{array}$ & DOD & $\begin{array}{l}\text { Bexarotene, topical steroids, } \\
\text { MTX, sunlight therapy, } \\
\text { photo therapy, vorinostat }\end{array}$ \\
\hline 4 & $\mathrm{M} / 50$ & $5 \%$ & CTCL-MF & $\begin{array}{l}\text { Bilateral axilla, } \\
\text { chest, abdomen }\end{array}$ & 6 & $\begin{array}{l}\text { Erythematous patches/scaly } \\
\text { plaque, some papules }\end{array}$ & Lost to $\mathrm{f} / \mathrm{u}$ & Topical steroids \\
\hline 7 & $\mathrm{M} / 83$ & $>95 \%$ & SS & Generalized & 3 & Generalized erythroderma & $\begin{array}{l}\text { Limited disease } \\
\text { progression }\end{array}$ & $\begin{array}{l}\text { Topical steroids, } \\
\text { photo therapy }\end{array}$ \\
\hline 9 & $\mathrm{M} / 67$ & NA & $\begin{array}{l}\text { CTCL- } \\
\text { MF/SS }\end{array}$ & NA & 9 & $\begin{array}{l}\text { Erythematous papules } \\
\text { and plaques }\end{array}$ & Lost to $\mathrm{f} / \mathrm{u}$ & NA \\
\hline 10 & $\mathrm{M} / 73$ & $>95 \%$ & CTCL-MF & Generalized & 6 & $\begin{array}{l}\text { Extensive hyperpigmentation } \\
\text { and erythroderma }\end{array}$ & DOD & $\begin{array}{l}\text { Bexarotene, NBUVB, } \\
\text { photo therapy }\end{array}$ \\
\hline 11 & $\mathrm{M} / 60$ & $10 \%$ & $\begin{array}{l}\text { CTCL- } \\
\text { MF/SS }\end{array}$ & $\begin{array}{l}\text { Upper extremities, } \\
\text { upper thighs, back }\end{array}$ & 6 & Plaques & Limited disease & $\begin{array}{l}\text { PUVA, bexarotene, topical } \\
\text { steroids, topical tacrolimus, } \\
\text { photo therapy, Excimer laser }\end{array}$ \\
\hline
\end{tabular}

BSA, body surface area; MTX, methotrexate; PUVA, psoralen plus UVA treatment; NBUVB, marrow band UVB therapy; DOD, died of disease.
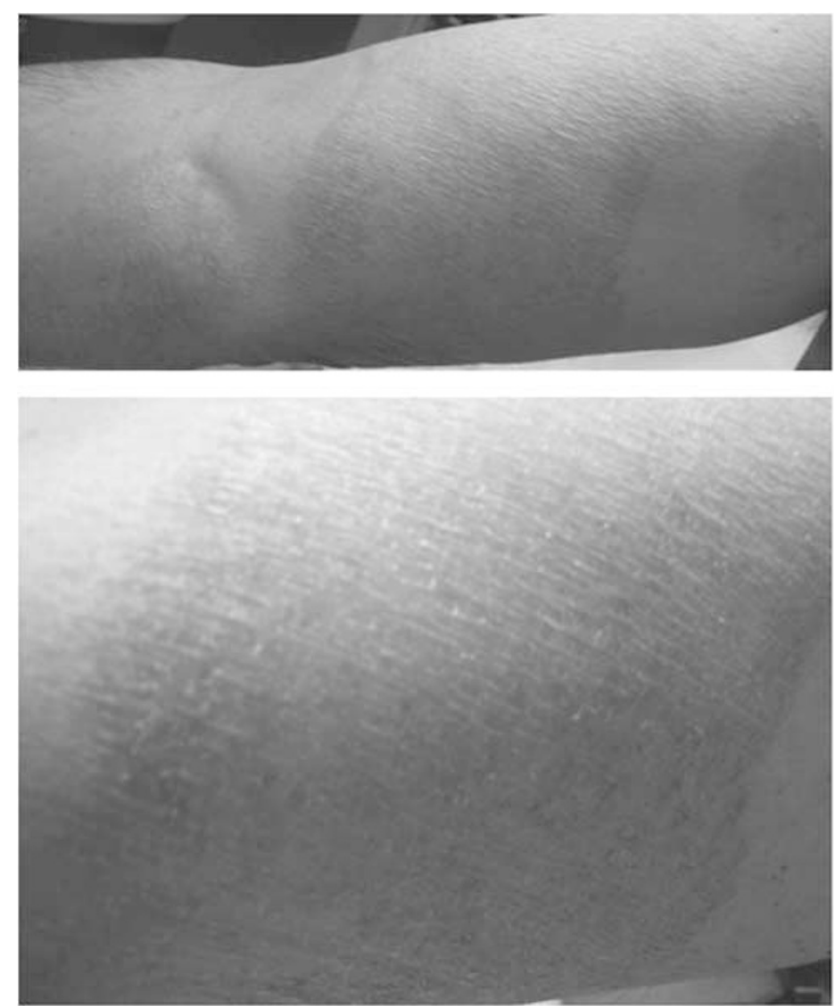

Figure 3 Gross morphology. Images demonstrate several erythematous patches with a slight amount of scale on the upper arm. Images are from patient 11 .

epidermal staining discordance. EBV, as detected by in situ hybridization for EBER, was negative in all cases. Immunohistochemical staining for CD10 on a skin biopsy specimen revealed moderateto-strong staining of $10-40 \%$ of the lymphoid cells in 7/8, Figures 1, 4, and 5. Morphology confirmed that cellular CD10 expression was not due to polymorphonuclear neutrophils. In addition to staining of lymphoma cells, CD10 expression was noted in and around hair follicles and in lymphomaassociated dermal fibroblasts and reticulin fibers as previously reported, Figure $5(2-10,42)$. CD10 immunohistochemistry staining was difficult to interpret in some specimens due to strong staining of the lymphoma-associated dermal fibroblasts and reticulin, Figure 5. Similar reactivity has been noted in association with non-hematopoietic and lymphoid cutaneous neoplasms and inflammatory skin conditions. ${ }^{6-10,42}$

One patient (patient 9) demonstrated only rare CD10 $(+)$ cells by immunohistochemistry despite having $\mathrm{CD} 10(+)$ mycosis fungoides/Sezary syndrome cells in the peripheral blood. This patient had $5-15 \%$ abnormal CD10 $(+) C D 4(+)$ T cells detected in the blood in eight separate samples over 3 years. The abnormal CD10 $(+)$ cells in blood resided in a subpopulation of large lymphoid cells as determined by side and forward angle light scatter by flow cytometry and CD10 expression on this subpopulation was only partial (data not shown). Few large cells were seen in the skin biopsy specimen.

Bcl-6 staining, in general, mirrored that of CD10 being detectable in $5-40 \%$ of the cells in the cases examined, Figures 1 and 5. Bcl-6 expression was evaluated in dermal lymphoid cells since epidermal keratinocytes stained with Bcl-6 making identification of epidermal lymphoid cells difficult. Epidermal keratinocyte reactivity of Bcl-6 has been previously reported. ${ }^{49}$ PCR for T-cell receptor $\gamma$ chain gene rearrangement was performed in four of 
Table 3 Skin lesion histology in patients with CD10(+) CTCL-MF or SS

\begin{tabular}{|c|c|c|c|c|c|c|c|c|c|c|c|c|}
\hline$P t$ & $\begin{array}{l}\text { Epidermi- } \\
\text { tropism }\end{array}$ & $\begin{array}{l}\text { Dermal } \\
\text { density }\end{array}$ & Location & $\begin{array}{l}C D 4 / \\
C D 8\end{array}$ & $\begin{array}{c}C D 45 R B / C D 45 R O \\
\text { discord }\end{array}$ & $\begin{array}{c}\% \text { Atypical } \\
\text { cells }\end{array}$ & $E B V$ & CD10 & $B c l-6$ & $P D-1$ & $\begin{array}{c}C X C L- \\
13\end{array}$ & $\begin{array}{l}\text { TCR } \\
\text { PCR }\end{array}$ \\
\hline 1 & $2-3$ & 2 & Superficial & 10:1 & Yes & $5-10 \%$ & Neg & $\begin{array}{l}10- \\
20 \%\end{array}$ & $\begin{array}{l}10- \\
20 \%\end{array}$ & $50 \%$ & $<5 \%$ & Neg \\
\hline 2 & 1 & 2 & Superficial & 10:1 & Yes & $20-30 \%$ & Neg & $40 \%$ & $\begin{array}{l}10- \\
20 \%\end{array}$ & $\begin{array}{c}30- \\
40 \%\end{array}$ & $<5 \%$ & ND \\
\hline 3 & 1 & 2 & Superficial & 10:1 & No & $10 \%$ & Neg & $20 \%$ & $20 \%$ & $10 \%$ & $\begin{array}{l}10- \\
20 \%\end{array}$ & ND \\
\hline 4 & 1 & 1 & Superficial & 10:1 & No & $<5 \%$ & Neg & $\begin{array}{l}20- \\
30 \%\end{array}$ & $\begin{array}{c}20- \\
30 \%\end{array}$ & $\begin{array}{l}20- \\
30 \%\end{array}$ & $<5 \%$ & Pos \\
\hline 7 & $0-1$ & $1-2$ & Superficial & $5-10: 1$ & Yes & $30 \%$ & Neg & $\begin{array}{l}20- \\
30 \%\end{array}$ & $20 \%$ & $50 \%$ & $<5 \%$ & Pos \\
\hline 9 & $2-3$ & 3 & Superficial & $>20: 1$ & No & $10-20 \%$ & Neg & $<2 \%$ & $2-5 \%$ & $5 \%$ & $<5 \%$ & Pos \\
\hline 10 & $2-3$ & 2 & Superficial & $10: 1$ & No & $50 \%$ & Neg & $\begin{array}{c}30- \\
40 \%\end{array}$ & $\begin{array}{c}30- \\
40 \%\end{array}$ & $\begin{array}{l}50- \\
60 \%\end{array}$ & $5 \%$ & $\operatorname{Pos}^{\mathrm{a}}$ \\
\hline 11 & 2 & 2 & Superficial & 10:1 & Yes & $30 \%$ & Neg & $\begin{array}{l}20- \\
30 \%\end{array}$ & $\begin{array}{l}20- \\
30 \%\end{array}$ & $\begin{array}{l}20- \\
30 \%\end{array}$ & $20 \%$ & Pos \\
\hline
\end{tabular}

aTCR Vbeta analysis performed on peripheral blood confirmed clonality.
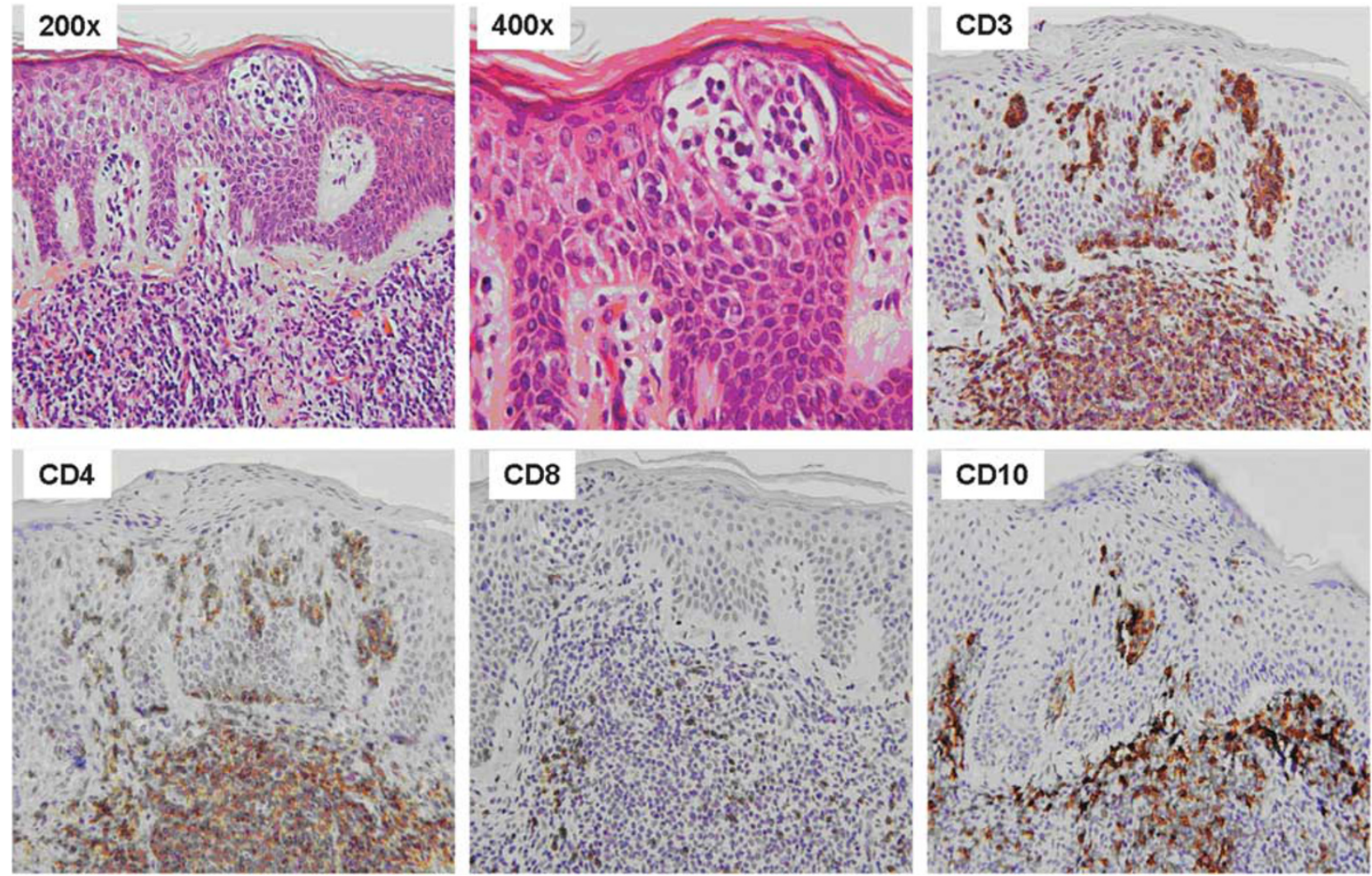

Figure 4 CD10 expression in mycosis fungoides by immunohistochemistry in a skin biopsy. Hematoxylin and eosin-stained tissues sections demonstrate acanthotic epidermis with prominent epidermotropic lymphocytes forming Pautrier microabscesses and a dense lymphocytic infiltrate in the upper dermis. Immunohistochemical staining for CD3, CD4, CD8, and CD10 is shown revealing the epidermotropic lymphocytes are CD3 $(+)$, CD4 $(+)$, CD8 $(-)$, and CD10 $(+)$. Some CD10 staining by immunohistochemistry appears to be arising from fibroblasts associated with the lymphoma. Images are from a skin biopsy from patient 1. 

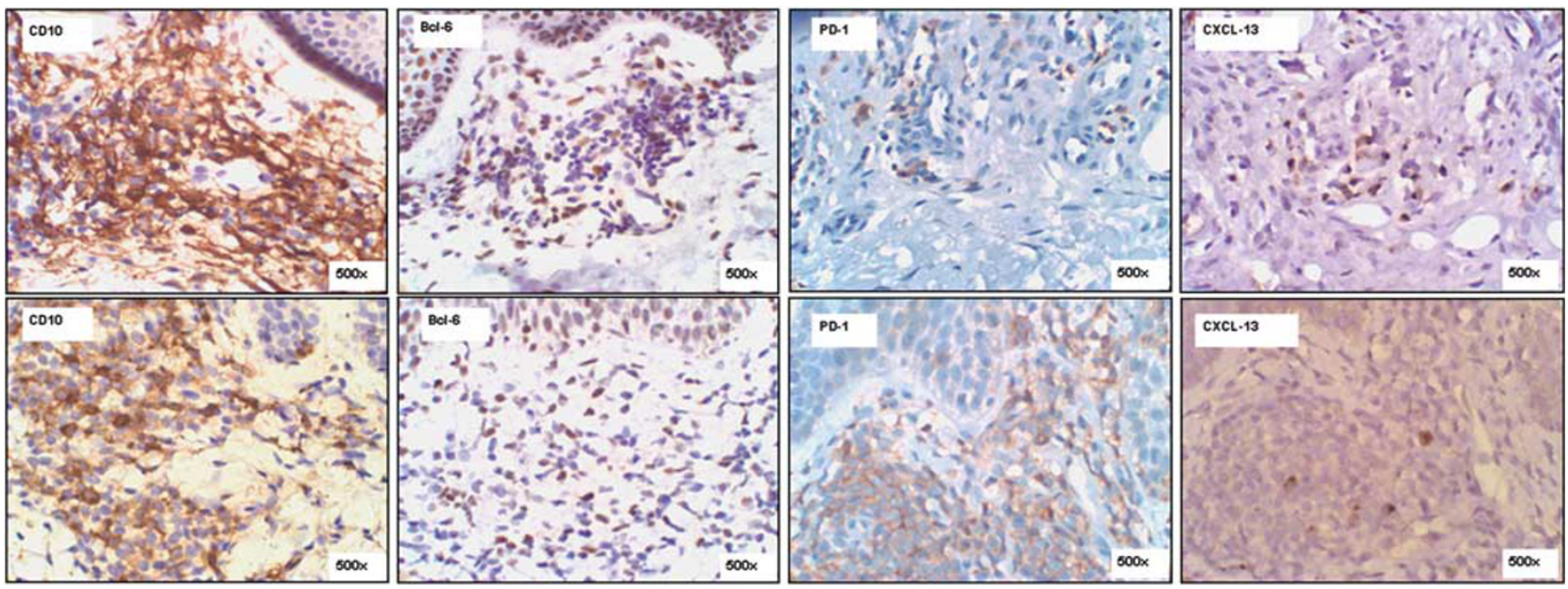

Figure 5 Follicular center helper T-cell marker staining of lymphoma cells. Staining for CD10, Bcl-6, PD-1, and CXCL-13 in two cases are shown. Immunohistochemical staining for CD10 was difficult to interpret in many cases due to the staining of dermal fibroblasts in close association with the lymphoma cells. In top (patient 3), CD10 staining of dermal fibroblasts is quite strong partially obscuring lymphoma cell specific reactivity. Bottom (patient 10), dermal fibroblast CD10 staining is present but not as intense as to obscure lymphoma cell reactivity. Bcl-6 and PD-1 staining mirrored that of CD10 although PD-1 staining was more abundant in some samples (eg, patient 10, bottom). CXCL-13 stained significantly fewer cells than other follicular center helper T-cell markers in most cases. Staining in patient 3 (top) was similar to PD-1, Bcl-6, and CD10 but only a small percentage of cells were stained in the specimen from patient 10 (bottom).

Table 4 FCM phenotype of CD10(+) cases

\begin{tabular}{ccccccccccccccc}
\hline Patient & \multirow{2}{*}{ Dx } & CD2 & CD3 & CD4 & CD5 & CD7 & CD8 & CD10 & CD25 & CD26 & CD30 & HLA-DR & CD45RO & CD45RA \\
\hline \multirow{2}{*}{1} & CTCL-MF & Mod & Dim & Dim & Bright & Neg & Neg & Partial & Dim & Neg & Neg & Neg & Mod & Neg \\
2 & CTCL-MF & Mod & Dim & Mod & Mod & Mod & Neg & Mod & ND & Neg & Neg & Dim & ND & ND \\
3 & SS & Mod & Dim & Mod & Mod & Partial & Neg & Partial & Dim & Neg & Partial & Neg & Bright & Neg \\
4 & CTCL-MF & Mod & Dim & Mod & Mod & Neg & Neg & Mod & Dim & Dim & Neg & Dim & Mod & Neg \\
7 & SS & Mod & Dim & Dim & Mod & Neg & Neg & Dim & Dim & Neg & Neg & Neg & Dim & Dim \\
9 & CTCL-MF & Mod & Dim & Mod & Bright & Partial & Neg & Partial & Mod & Neg & Neg & Neg & Dim & Neg \\
10 & CTCL-MF->SS & Mod & Dim & Mod & Bright & Neg & Neg & Partial & Dim & Neg & Neg & Neg & Bright & Neg \\
11 & CTCL-MF/SS & Mod & Dim & Mod & Mod & Neg & Neg & Dim & Dim & Neg & Neg & Neg & Mod & Neg \\
\hline
\end{tabular}

the six patients and a dominant rearranged band was detected in three. An additional patient's T cells were shown to be clonal in peripheral blood by use of flow cytometry and TCR Vbeta region antibodies. ${ }^{50}$

PD-1 expression was membranous and moderate to strong and was similar to that of CD10 and Bcl-6, Figure 5. PD-1 appeared to stain more cells than either CD10 or Bcl-6 in three of the samples, Figure 5. Little background staining was noted. CXCL-13 expression was less impressive being detected in a significant fraction of cells (10-20\%) in only two of eight cases, Figure 5. One of these patients had Sezary syndrome and the other had mycosis fungoides with Sezary syndrome. Staining was granular and cytoplasmic.

Flow Cytometry. Flow cytometric analysis of a skin biopsy was performed in 6/8 patients. Five of the six had an abnormal T-cell population detected, all of which were CD10 $(+)$, Figures 1 and 2. One patient's (patient 11) skin biopsy flow cytometry did not detect an abnormal T-cell population but morpho- logically the biopsy was uninvolved by mycosis fungoides at the time.

By flow cytometry, the cellular phenotype was indistinguishable from mycosis fungoides/Sezary syndrome except for the expression of CD10, Table $4 .{ }^{41,45-47}$ Diminished CD3 expression was present in all cases (8/8). In all, 5/8 lacked expression of CD7, two had partial expression of CD7, and one was $\operatorname{CD} 7(+)$. CD26 was absent in $6 / 7$ and weakly expressed in another. CD10 expression was partial in 4/8 and dimly expressed in two others.

Blood Findings. Flow cytometry was performed on peripheral blood in 5/8 patients. Peripheral blood morphology was evaluated in another. Two patients did not have blood evaluated. All patients evaluated for peripheral blood involvement (6/6) had abnormal cells detected. Enumeration of the circulating lymphoma by flow cytometry demonstrated a varying degree of circulating lymphoma cells (range: $200 / \mu \mathrm{l}-6,200 / \mu \mathrm{l})$. In four patients, the level was $>1000 / \mu \mathrm{l}$ in one or more analysis (stage B2 in ISCL/ EORTC staging scheme). ${ }^{51}$ Two of these patients 
were classified as Sezary syndrome and two as mycosis fungoides with Sezary syndrome. One patient (patient 10) had circulating lymphoma cells but CD10 was detected on the cells in only 1/6 involved blood samples. CD10 expression in the specimen was very weak and partial. CD10 expression was present in the lymphoma cells from a skin biopsy by flow cytometry and immunohistochemistry from this patient, however, Figure 1.

Clinical Follow-Up. Clinical follow-up data were reviewed as available. Mean follow-up was 6.6 years with two patients lost to follow-up, Table 1. Two of the eight patients died of disease, 6 and 7 years postdiagnosis. Three patients have had limited disease progression at last follow-up, one patient progressed from stage IB to IIA.

\section{Discussion}

We describe eight cases of mycosis fungoides or Sezary syndrome that express follicular center helper T-cell markers CD10, Bcl-6, and PD-1. The cases were initially identified as CD10 $(+) \operatorname{CD} 4(+)$ T-cell neoplasms through flow cytometric analysis of skin biopsies or peripheral blood samples. CD10 expression was also observed in tissue biopsy by immunohistochemistry in seven of eight cases in which tissue was evaluated. The findings indicate that follicular center helper T-cell markers CD10, Bcl-6, and PD-1 may be expressed in mycosis fungoides or Sezary syndrome, suggesting a follicular center helper T-cell origin or follicular center helper T-cell differentiation capability for these lesions. Expression of these markers could potentially lead to confusion in distinguishing mycosis fungoides from other follicular center helper T-cell marker positive cutaneous T-cell lymphomas such as primary cutaneous CD4 $(+)$ small/medium-sized pleomorphic T-cell lymphoma or angioimmunoblastic T-cell lymphoma with cutaneous involvement.

Only a few previous studies have investigated the expression of follicular center helper T-cell markers in mycosis fungoides or Sezary syndrome. The best studied of these is PD-1. There are conflicting reports about the frequency of PD-1 expression in mycosis fungoides. Wada et al. ${ }^{52}$ evaluated 41 mycosis fungoides and Sezary syndrome cases for the expression of PD-1. They found PD-1 expression in $56 \%$ of cases including $8 / 11(73 \%)$ of Sezary syndrome samples examined. The authors noted a slight increase in the frequency of PD-1-positive cases in mycosis fungoides in tumor stage (60\%) compared with plaque/patch stage (40\%). Kantekure et al. ${ }^{53}$ also noted frequent expression of PD-1 in mycosis fungoides; however, these authors identified decreasing expression of PD-1 in the more advanced forms of mycosis fungoides. PD-1 was detected in all (9/9) patch and plaque phases of mycosis fungoides. However, PD-1 was expressed less frequently $(3 / 6,50 \%)$ at the tumor stage. The authors noted that PD-1 expression loss preferentially affected the large lymphoid cells. They did not evaluate Sezary syndrome cases. Roncador et al. ${ }^{31}$ evaluated PD-1 in a wide array of lymphomas including mycosis fungoides and noted expression in 5/9 mycosis fungoides. These authors also examined the follicular center helper T-cellassociated marker SAP in six mycosis fungoides cases but did not detect significant expression in any. ${ }^{31}$ In contrast to these studies, Cetinozman et al. ${ }^{34}$ identified infrequent expression of PD-1 in mycosis fungoides observing reactivity in only 2 of $21(9.5 \%)$ of cases. The reason for the reported differences in the frequency of PD-1 expression in mycosis fungoides is unclear but may relate in part to specific reagents used and the stage of disease examined. Although all of our cases were PD-1 positive, we only examined those mycosis fungoides or Sezary syndrome specimens that were known to be $\operatorname{CD} 10(+)$.

Other follicular center helper T-cell markers have not been evaluated to any significant degree in mycosis fungoides. Ortonne et al. ${ }^{42}$ evaluated the usefulness of CXCL-13 for the detection of angioimmunoblastic T-cell lymphoma in skin lesions. They did not detect expression of CXCL-13 in three skin biopsies involved by mycosis fungoides in their study. ${ }^{42}$ CXCL-13 immunoreactivity was encountered infrequently (2 of $14(14 \%)$ ) in mycosis fungoides cutaneous lesions studied by Picchio et al. ${ }^{54}$ However, these authors noted that CXCL-13 was commonly expressed in Sezary syndrome samples (13 of 16, 81\%)). The increase frequency of expression of CXCL-13 between Sezary syndrome and mycosis fungoides observed by these authors was similar to the increased frequency of PD-1 expression on Sezay syndrome cells compared with mycosis fungoides cells noted by Wada et al. ${ }^{52}$ Although we did not evaluate expression of follicular center helper T-cell markers by mycosis fungoides stage, it is interesting to note that circulating lymphoma cells were detected all (6/6) patients in which blood was evaluated. Four of five patients in which flow cytometry was used to enumerate the circulating cells had one or more sample in which mycosis fungoides/Sezary syndrome cells were present at $>1000 / \mu \mathrm{l}$, indicative of stage B2 disease in the ISCL staging scheme. Two of these patients were CXCL-13 positive. Our data therefore appear to support the supposition that follicular center helper T-cell expression may occur at higher frequency in Sezary syndrome than in more limited stage mycosis fungoides.

Bcl-6 and CD10 have not been the formally evaluated in mycosis fungoides or Sezary syndrome. Chubachi et al. ${ }^{55}$ published a case report of a CD10 $(+)$ Sezary syndrome in 1994 but we are unaware of other similar cases. CD10 and Bcl-6 were evaluated secondarily by Cetinozman et al. ${ }^{34}$ in their two PD-1 positive mycosis fungoides cases. 
In both cases, the cells expressed BCL-6 and CXCL13. CD10 however, was only expressed in one of the two cases. ${ }^{34}$ The authors did not evaluate Bcl-6 and CD10 in PD-1( - ) mycosis fungoides.

The expression of follicular center helper T-cell markers in mycosis fungoides could lead to diagnostic confusion with angioimmunoblastic T-cell lymphoma or primary cutaneous CD4 $(+)$ small/ medium-sized pleomorphic T-cell lymphoma. Interestingly, although PD-1, BCL-6, and CXCL-13 are all expressed on the neoplastic $\mathrm{T}$ cells in primary cutaneous $\mathrm{CD} 4(+)$ small/medium-sized pleomorphic T-cell lymphoma, CD10 appears to be infrequently expressed in these lesions. ${ }^{20,34}$ Cetinozman et al. ${ }^{34}$ did not detect expression of CD10 on any of their cases of primary cutaneous CD4 $(+)$ small/medium-sized pleomorphic T-cell lymphoma (0/11)). In the study of primary cutaneous $\mathrm{CD} 4(+)$ small/medium-sized pleomorphic T-cell lymphoma by Pinilla et al., ${ }^{20}$ CD10 was observed to be expressed in only 4 of the 15 cases; all but one demonstrating weak staining. The infrequent expression of CD10 in these tumors may explain why we did not identify a primary cutaneous CD4 $(+)$ small/medium-sized pleomorphic T-cell lymphoma in our series which was based on the detection of CD10. Bcl-6, on the contrary, appears to be ubiquitously expressed in these tumors. ${ }^{20,34}$ In all, 6/8 of our follicular center helper T-cell marker positive mycosis fungoides cases had a CD10 (+)Bcl-6(+)CXCL-13(-) phenotype. Based on these data, although limited, a cutaneous CD4 $(+)$ T-cell lesion with such a phenotype would favor a follicular center helper T-cell marker positive mycosis fungoides rather than primary cutaneous CD4 $(+)$ small/medium-sized pleomorphic T-cell lymphoma.

Although we did not evaluate parameters that might distinguish angioimmunoblastic T-cell lymphoma from a follicular center helper T-cell $(+)$ mycosis fungoides in a skin biopsy we would make the following comments. CD10 expression is seen in roughly $70 \%$ of angioimmunoblastic T-cell lymphoma cases and although useful for detecting angioimmunoblastic T-cell lymphoma in most non-nodal sites, it has less utility in skin biopsies. ${ }^{27,41,42,43,56}$ We do not know exactly the percentage of mycosis fungoides cases that are $\operatorname{CD} 10(+)$ but based on our flow cytometry data, roughly $16.7 \%$ (6/36) of mycosis fungoides cases were found to express CD10. An evaluation of a large number of mycosis fungoides cases for follicular center helper T-cell markers including CD10 and Bcl-6 would be necessary to determine more precisely the frequency of reactivity of these markers and their relationship to one another and, ultimately, their utility in distinguishing mycosis fungoides from angioimmunoblastic T-cell lymphoma. Currently, we would not recommend distinguishing angioimmunoblastic T-cell lymphoma from mycosis fungoides based on CD10 expression alone in a skin biopsy.
Morphologically bottom-heavy dermal infiltrates favor angioimmunoblastic T-cell lymphoma as we did not see deep infiltrates in our mycosis fungoides cases. Evaluation for PD-1 and CXCL-13 may be of use distinguishing angioimmunoblastic T-cell lymphoma from mycosis fungoides, although as noted above, PD-1 is expressed in a significant percentage of mycosis fungoides cases. CXCL-13 expression is less commonly expressed in mycosis fungoides. $\operatorname{EBV}(+)$ cells are present in a high percentage of angioimmunoblastic T-cell lymphoma cases and are not present in mycosis fungoides. ${ }^{41,44}$ However, $\operatorname{EBV}(+)$ cells are variably detected in the skin lesions of angioimmunoblastic T-cell lymphoma. ${ }^{57}$ The flow cytometry phenotype of angioimmunoblastic T-cell lymphoma and follicular center helper T-cell $(+)$ mycosis fungoides and Sezary syndrome in our study were similar although two of the three angioimmunoblastic T-cell lymphoma samples demonstrated abnormal bright expression of antigens (HLA-DR, CD2, and CD4) not normally overexpressed in mycosis fungoides or Sezary syndrome (data not shown). ${ }^{41,45-47}$ Overall, it may be difficult for the pathologist to distinguish a follicular center helper T-cell $(+)$ mycosis fungoides from angioimmunoblastic T-cell lymphoma based solely on histology and immunophenotype. A full evaluation of the patient's clinical picture still appears necessary to satisfactorily differentiate these processes.

Evaluation of CD10 and Bcl-6 by immunohistochemistry can be problematic due to reactivity of normal skin cells with these antibodies. ${ }^{2-5,49}$ Perifollicular dermal sheath fibroblasts and dermal fibroblasts may express CD10 in inflammatory and neoplastic skin conditions. ${ }^{2-8}$ We noted staining of this sort in some of our specimens. The strong staining of CD10 in dermal fibroblasts associated with the lymphoma cells made it difficult to identify lymphoma cell specific staining as has been previously noted. ${ }^{42}$ CD10 expression on abnormal CD4 $(+) \mathrm{T}$ cells by flow cytometry was easier to demonstrate. Bcl-6 is expressed in epidermal keratinocytes making evaluation of Bcl-6 expression in epidermal infiltrating lymphoma cells difficult. ${ }^{49}$ Dual staining immunohistochemical methods therefore might be the most helpful in evaluating these markers in tissue sections. We would advocate flow cytometry due to the multi-parameter capability of flow cytometers and the sensitivity afforded by the instrumentation. Flow cytometry evaluation of archived paraffin-embedded tissue sections, of course, is not possible. Regardless, based on the findings presented here, the identification of follicular center helper T-cell marker positive, particularly CD10 $(+)$ Bcl-6(+), T cells in skin involved by a T-cell lymphoproliferative process does not exclude mycosis fungoides or Sezary syndrome. Additionally, the expression of follicular center helper T-cell markers in mycosis fungoides or Sezary syndrome suggests follicular center helper T-cell differentiation 
or follicular center helper T-cell differentiation capability in some of these tumors.

\section{Acknowledgements}

We thank the members of the UH Case Medical Center Flow Cytometry Laboratory, Alison Edinger, Ebenezer Osei, Karen Schweitzer, and Georgetta Blidaru, for their help in making this manuscript possible.

\section{Disclosure/conflict of interest}

The authors declare no conflict of interest.

\section{References}

1 McIntosh GG, Lodge AJ, Watson P, et al. NCL-CD10270: a new monoclonal antibody recognizing CD10 in paraffin-embedded tissue. Am J Pathol 1999;154: 77-82.

2 Poblet E, Jiménez F. CD10 and CD34 in fetal and adult human hair follicles: dynamic changes in their immunohistochemical expression during embryogenesis and hair cycling. Br J Dermatol 2008;159:646-652.

3 Lee KJ, Choi YL, Kim WS, et al. CD10 is expressed in dermal sheath cells of the hair follicles in human scalp. Br J Dermatol 2006;155:858-860.

4 Olerud JE, Usui ML, Seckin D, et al. Neutral endopeptidase expression and distribution in human skin and wounds. J Invest Dermatol 1999;112:873-881.

5 Xie L, Takahara M, Nakahara T, et al. CD10-bearing fibroblasts may inhibit skin inflammation by downmodulating substance P. Arch Dermatol Res 2011; 303:49-55.

6 Takahara M, Chen S, Kido M, et al. Stromal CD10 expression, as well as increased dermal macrophages and decreased Langerhans cells, are associated with malignant transformation of keratinocytes. J Cutan Pathol 2009;36:668-674.

7 Bilalovic N, Sandstad B, Golouh R, et al. CD10 protein expression in tumor and stromal cells of malignant melanoma is associated with tumor progression. Mod Pathol 2004;17:1251-1258.

8 Carrel S, Zografos L, Schreyer M, et al. Expression of CALLA/CD10 on human melanoma cells. Melanoma Res 1993;3:319-323.

9 de Feraudy S, Mar N, McCalmont TH. Evaluation of CD10 and procollagen 1 expression in atypical fibroxanthoma and dermatofibroma. Am J Surg Pathol 2008;32:1111-1122.

10 Kanitakis J, Bourchany D, Claudy A. Expression of the CD10 antigen (neutral endopeptidase) by mesenchymal tumors of the skin. Anticancer Res 2000;20: 3539-3544.

11 Aguilera NS, Tomaszewski MM, Moad JC, et al. Cutaneous follicle center lymphoma: a clinicopathologic study of 19 cases. Mod Pathol 2001;14:828-835.

12 McCormack RT, Nelson RD, LeBien TW. Structure/ function studies of the common acute lymphoblastic leukemia antigen (CALLA/CD10) expressed on human neutrophils. J Immunol 1986;137:1075-1082.
13 Wang C, Hillsamer P, Kim CH. Phenotype, effector function, and tissue localization of PD-1-expressing human follicular helper T cell subsets. BMC Immunol 2011;12:53.

14 Crotty S. Follicular helper CD4 T cells (TFH). Annu Rev Immunol 2011;29:621-663.

15 Marafioti T, Paterson JC, Ballabio E, et al. The inducible T-cell co-stimulator molecule is expressed on subsets of $\mathrm{T}$ cells and is a new marker of lymphomas of $\mathrm{T}$ follicular helper cell-derivation. Haematologica 2010;95:432-439.

16 Iwai Y, Okazaki T, Nishimura H, et al. Microanatomical localization of PD-1 in human tonsils. Immunol Lett 2002;83:215-220.

17 Chtanova T, Tangye SG, Newton R, et al. T follicular helper cells express a distinctive transcriptional profile, reflecting their role as non-Th1/Th2 effector cells that provide help for B cells. J Immunol 2004; 173:68-78

$18 \mathrm{Kim} \mathrm{CH}$, Lim HW, Kim JR, et al. Unique gene expression program of human germinal center T helper cells. Blood 2004;104:1952-1960.

19 Nurieva RI, Chung Y, Martinez GJ, et al. Bcl6 mediates the development of T follicular helper cells. Science 2009;325:1001-1005.

20 Rodríguez Pinilla SM, Roncador G, Rodríguez-Peralto $\mathrm{JL}$, et al. Primary cutaneous CD4+ small/mediumsized pleomorphic T-cell lymphoma expresses follicular T-cell markers. Am J Surg Pathol 2009;33:81-90.

21 Rodríguez-Pinilla SM, Atienza L, Murillo C, et al. Peripheral T-cell lymphoma with follicular T-cell markers. Am J Surg Pathol 2008;32:1787-1799.

22 Dupuis J, Boye K, Martin N, et al. Expression of CXCL13 by neoplastic cells in angioimmunoblastic T-cell lymphoma (AITL): a new diagnostic marker providing evidence that AITL derives from follicular helper T cells. Am J Surg Pathol 2006;30:490-494.

23 Grogg KL, Attygalle AD, Macon WR, et al. Expression of CXCL13, a chemokine highly upregulated in germinal center T-helper cells, distinguishes angioimmunoblastic T-cell lymphoma from peripheral T-cell lymphoma, unspecified. Mod Pathol 2006;19: 1101-1107.

24 de Leval L, Rickman DS, Thielen C, et al. The gene expression profile of nodal peripheral T-cell lymphoma demonstrates a molecular link between angioimmunoblastic T-cell lymphoma (AITL) and follicular helper T (TFH) cells. Blood 2007;109:4952-4963.

$25 \mathrm{Yu} \mathrm{H}$, Shahsafaei A, Dorfman DM. Germinal-center T-helper-cell markers PD-1 and CXCL13 are both expressed by neoplastic cells in angioimmunoblastic T-cell lymphoma. Am J Clin Pathol 2009;131:33-41.

26 Huang Y, Moreau A, Dupuis J, et al. Peripheral T-cell lymphomas with a follicular growth pattern are derived from follicular helper T cells (TFH) and may show overlapping features with angioimmunoblastic T-cell lymphomas. Am J Surg Pathol 2009;33:682-690.

27 Attygalle A, Al-Jehani R, Diss TC, et al. Neoplastic $\mathrm{T}$ cells in angioimmunoblastic T-cell lymphoma express CD10. Blood 2002;99:627-633.

28 Rodriguez-Justo M, Attygalle AD, Munson P, et al. Angioimmunoblastic T-cell lymphoma with hyperplastic germinal centres: a neoplasia with origin in the outer zone of the germinal centre? Clinicopathological and immunohistochemical study of 10 cases with follicular T-cell markers. Mod Pathol 2009;22: 753-761. 
29 Zhan HQ, Li XQ, Zhu XZ, et al. Expression of follicular helper $\mathrm{T}$ cell markers in nodal peripheral $\mathrm{T}$ cell lymphomas: a tissue microarray analysis of 162 cases. J Clin Pathol 2011;64:319-324.

30 Stacchini A, Demurtas A, Aliberti S, et al. The usefulness of flow cytometric CD10 detection in the differential diagnosis of peripheral T-cell lymphomas. Am J Clin Pathol 2007;128:854-864.

31 Roncador G, García Verdes-Montenegro JF, et al. Expression of two markers of germinal center T cells (SAP and PD-1) in angioimmunoblastic T-cell lymphoma. Haematologica 2007;92:1059-1066.

32 de Leval L, Savilo E, Longtine J, et al. Peripheral T-cell lymphoma with follicular involvement and a CD4+ I bcl-6 + phenotype. Am J Surg Pathol 2001;25:395-400.

33 Baseggio L, Traverse-Glehen A, Berger F, et al. CD10 and ICOS expression by multiparametric flow cytometry in angioimmunoblastic T-cell lymphoma. Mod Pathol 2011;24:993-1003.

34 Cetinözman F, Jansen PM, Willemze R. Expression of programmed death-1 in primary cutaneous CD4positive small/medium-sized pleomorphic T-cell lymphoma, cutaneous pseudo-T-cell lymphoma, and other types of cutaneous T-cell lymphoma. Am J Surg Pathol 2012;36:109-116.

35 Bacon CM, Paterson JC, Liu H, et al. Peripheral T-cell lymphoma with a follicular growth pattern: derivation from follicular helper $\mathrm{T}$ cells and relationship to angioimmunoblastic T-cell lymphoma. Br J Haematol 2008;143:439-441.

36 Friedmann D, Wechsler J, Delfau MH, et al. Primary cutaneous pleomorphic small T-cell lymphoma. A review of 11 cases. The French Study Group on Cutaneous Lymphomas. Arch Dermatol 1995;131:1009-1015.

37 Grogg KL, Jung S, Erickson LA, et al. Primary cutaneous CD4-positive small/medium-sized pleomorphic T-cell lymphoma: a clonal T-cell lymphoproliferative disorder with indolent behavior. Mod Pathol 2008;21:708-715.

38 Balaraman B, Conley JA, Sheinbein DM. Evaluation of cutaneous angioimmunoblastic T-cell lymphoma. J Am Acad Dermatol 2011;65:855-862.

39 Bernstein JE, Soltani K, Lorincz AL. Cutaneous manifestations of angioimmunoblastic lymphadenopathy. J Am Acad Dermatol 1979;1:227-232.

40 Martel P, Laroche L, Courville P, et al. Cutaneous involvement in patients with angioimmunoblastic lymphadenopathy with dysproteinemia: a clinical, immunohistological, and molecular analysis. Arch Dermatol 2000;136:881-886.

41 Smith SH, Campo E, Harris NL, et al. editors.WHO Classification of Tumours of Haematopoietic and Lymphoid Tissues. 4th ed. IARC: Lyon; 2008, pp 271-319.

42 Ortonne N, Dupuis J, Plonquet A, et al. Characterization of CXCL13 + neoplastic $\mathrm{T}$ cells in cutaneous lesions of angioimmunoblastic T-cell lymphoma (AITL). Am J Surg Pathol 2007;31:1068-1076.

43 Mourad N, Mounier N, Brière J, et al. Clinical, biologic, and pathologic features in 157 patients with angioimmunoblastic T-cell lymphoma treated within the Groupe d'Etude des Lymphomes de l'Adulte (GELA) trials. Blood 2008;111:4463-4470.
44 Weiss LM, Jaffe ES, Liu XF, et al. Detection and localization of Epstein-Barr viral genomes in angioimmunoblastic lymphadenopathy and angioimmunoblastic lymphadenopathy-like lymphoma. Blood 1992;79:1789-1795.

45 Oshtory S, Apisarnthanarax N, Gilliam AC, et al. Usefulness of flow cytometry in the diagnosis of mycosis fungoides. J Am Acad Dermatol 2007;57: 454-462.

46 Meyerson HJ. Flow cytometry for the diagnosis of mycosis fungoides. G Ital Dermatol Venereol 2008;143: 21-41.

47 Meyerson HJ. Flow cytometry as a tool for the diagnosis of cutaneous T cell lymphoma. J Clin Derm 2010;1:31-42.

48 Ismail SA, Han R, Sanborn SL, et al. Immunohistochemical staining for CD45R isoforms in paraffin sections to diagnose mycosis fungoides-type cutaneous T-cell lymphoma. J Am Acad Dermatol 2007; 56:635-642.

49 Yoshida T, Fukuda T, Okabe S, et al. The BCL6 gene is predominantly expressed in keratinocytes at their terminal differentiation stage. Biochem Biophys Res Commun 1996;228:216-220.

50 Willemze R, Jaffe ES, Burg G, et al. WHO-EORTC classification for cutaneous lymphomas. Blood 2005; 105:3768-3785.

51 Olsen E, Vonderheid E, Pimpinelli N, et al. Revisions to the staging and classification of mycosis fungoides and Sezary syndrome: a proposal of the International Society for Cutaneous Lymphomas (ISCL) and the cutaneous lymphoma task force of the European Organization of Research and Treatment of Cancer (EORTC). Blood 2007;110:1713-1722.

52 Wada DA, Wilcox RA, Harrington SM, et al. Programmed death 1 is expressed in cutaneous infiltrates of mycosis fungoides and Sézary syndrome. Am J Hematol 2011;86:325-327.

53 Kantekure K, Yang Y, Raghunath P, et al. Expression Patterns of the Immunosuppressive Proteins PD-1/ CD279 and PD-L1/CD274 at Different Stages of Cutaneous T-Cell Lymphoma/Mycosis Fungoides. Am J Dermatopathol 2012;34:126-128.

54 Picchio MC, Scala E, Pomponi D, et al. CXCL13 is highly produced by Sézary cells and enhances their migratory ability via a synergistic mechanism involving CCL19 and CCL21 chemokines. Cancer Res 2008;68:7137-7146.

55 Chubachi A, Ishino T, Satoh N, et al. Common acute lymphoblastic leukemia antigen (CD10)-positive Sézary's syndrome. Am J Hematol 1994;45:271-272.

56 Attygalle AD, Diss TC, Munson P, et al. CD10 expression in extranodal dissemination of angioimmunoblastic T-cell lymphoma. Am J Surg Pathol 2004;28:54-61.

57 Yoon GS, Choi YK, Bak H, et al. Angioimmunoblastic $\mathrm{T}$ cell lymphomas: frequent cutaneous skin lesions and absence of human herpes viruses. Ann Dermatol 2009;21:1-5.

58 Clark RA, Shackelton JB, Watanabe R, et al. Highscatter T cells: a reliable biomarker for malignant $\mathrm{T}$ cells in cutaneous T-cell lymphoma. Blood 2011;117: 1966-1976. 